\title{
Names, They Are A-Changing
}

\author{
Anastasia Thanukos
}

Published online: 24 July 2010

(C) The Author(s) 2010. This article is published with open access at Springerlink.com

Keywords Classification · Population thinking · Nature of science $\cdot$ Media $\cdot$ Teaching

\section{Introduction}

The fossil record of human ancestors is dense compared to the fossil record for many other branches on the tree of life. For example, though thousands of fossils from hominins (organisms that are more closely related to us than they are to chimpanzees) have been discovered, we have only a handful from the chimp lineage (McBrearty and Jablonksi 2005). Despite this richness of fossil material, we regularly hear about scientific controversies regarding which species these ancient human forms represent and how they are related to one another. For example, in this issue, Strait (2010) describes debates over whether several preaustralopith fossils reside on our branch of the tree of life, over the relationship between Australopithecus anamensis and Australopithecus afarensis, and over the relationship between Australopithecus garhi and our own genus, Homo. Additionally, the human lineage is not alone in its frequent name changes and shifting familial relationships. In this issue, McNulty (2010) describes similar debates over the naming of and relationships among extinct non-human apes represented in the dense Miocene fossil record.

\footnotetext{
A. Thanukos $(\bowtie)$

University of California Museum of Paleontology,

1101 Valley Life Sciences Building,

Berkeley, CA 94720-4780, USA

e-mail: thanukos@berkeley.edu

URL: http://evolution.berkeley.edu
}

How should students interpret the frequent name changes experienced by our extinct relatives? What should they make of headlines that trumpet major revisions of the branching patterns on our limb of the tree of life? From the popular press' depiction of these scientific controversies, some students are likely to come away with the message that, when it comes to human evolutionary history and the human fossil record, scientists don't know what they are talking about. However, instruction on population thinking and classification, as well as on the process of science, can help students avoid such misleading interpretations. Here, we will review three major issues that can help students understand, assimilate, and appropriately interpret such media coverage.

\section{Species are Populations, Not Prototypes}

First, to understand how scientists can disagree over which species a fossil represents, students need population thinking skills (Mayr 1984) - that is, they need to view species not as discrete entities but as assemblages of individuals whose characteristics vary slightly from one another and vary over time as older individuals are replaced by younger ones. When scientists discover a fossil, they often discover a fragment of a single individual, but members of all species vary from individual to individual. When we are studying the partial, fossil remains of an organism, it can be exceedingly difficult to tell whether it is similar enough to a known species to be reliably placed in that group. As McNulty (2010) points out in this issue, even males and females of the same species can have remarkably different characteristics (e.g., in the size of their canines), and this can complicate species identification in 
the fossil record. Does a fossil skull from a small-toothed, small-bodied ape represent a new species or simply a female from an already named species? Unless DNA can be recovered from the fossil or another skeletal indicator of sex is found, this is a difficult question to answer.

In addition, the physical traits of individuals within a species vary over time as they develop and grow. For example, until recently, the pachycephalosaur dinosaurs Dracorex hogwartsia, Stygimoloch spinifer, and Pachycephalosaurus wyomingensis were considered separate species due to their size differences and differently shaped skulls. P. wyomingensis had a bulbous dome on the top of its head with relatively few spiky head ornaments, $D$. hogwartsia had a flat head covered in spikes, and $S$. spinifer fell in between these two extremes. However, when scientists studied the fossils for signs of sexual maturity and regions of bone growth, they found that these three forms most likely represent three stages of growth in a single species rather than three separate species (Horner and Goodwin 2009). Though the fossils look very different from one another, they are probably from the same species, $P$. wyomingensis. Figuring this out required detailed study of not just the shape and size of the bones but of the internal bone structure of the fossils, of growth patterns in modern organisms, and of the rock layers in which the fossils were found.

A prime example from human evolution highlighting the difficulty of figuring out whether a new fossil falls within the normal range of variation of a known species is Homo floresiensis, a small hominin discovered in Indonesia (Brown et al. 2004). Scientists have vigorously debated whether the unusually shaped and sized fossils represent a new species (H. floresiensis) or a modern human (Homo sapiens) with a disease such as microcephaly (e.g., see Jacob et al. 2006). However, with scattered fossils from just a few different individuals and only one skull (Morwood et al. 2005), making such judgments can be difficult. Multiple fossils from different individuals can give paleontologists an understanding of the natural range of variation encompassed by a species, and therefore help them make assessments about which fossil specimens should be grouped together into the same species. Unfortunately, the fossil record does not always cooperate by yielding sufficient fossils.

\section{Evolution Produces a Continuous Line of Descent}

Evolution is a natural process that produces an unbroken line of descent from our common ancestor that lived 3.8 billion years ago to all the organisms that have ever lived on Earth. However, to get a handle on all this diversity, biologists have to use discrete names to refer to different sections and offshoots of that line. The contrast between our need to classify organisms into neat groups and the messy, winding path of evolutionary descent sometimes leads to confusion about exactly what a particular organism should be called. This problem is compounded by many different approaches biologists take to define and distinguish species.

Different biologists in different fields studying different organisms often look at the idea of a species in different ways. For some, a species is a group of individuals that actually or potentially interbreed in nature. For some, a species is a group of individuals with physical and genetic similarities that set them apart from other organisms. For some, species are the smallest distinguishable branches on a phylogeny, that is, the smallest set of organisms that share an ancestor and can be distinguished from other such sets (see Thanukos 2009 for a review of phylogenetic classification). Some even argue that we should get rid of the idea of a species entirely (Mishler 1999)! With all these different perspectives, it is no surprise that biologists often vehemently disagree about what an organism ought to be called.

Furthermore, some of these definitions are particularly difficult to apply to extinct organisms known only via the fossil record. For example, the fossil record only rarely includes information that would help us recognize interbreeding. Even when it does, it may still highlight the inherent fuzziness of applying discrete names to continuous variation. As described by Harvati (2010) in this issue, recent genetic evidence recovered from Neanderthal fossils suggests that Neanderthals and modern humans interbred in Eurasia (Green et al. 2010), and some have argued that certain fossils represent hybrids between Neanderthals and modern humans (Duarte et al. 1999; Soficaru et al. 2007). The evidence suggests that these two groups interbred only to a limited extent. But just how much interbreeding would have had to have taken place for us to lump Neanderthals under the same name as modern humans? Clearly, even groups that scientists recognize as distinct, like Neanderthals and humans, may be seen to have fuzzy borders when one looks closely enough at their edges.

Extinct organisms known only from the fossil record are often named on the basis of physical characteristics alone. However, this can lead to other naming challenges. For example, we know that populations, and hence species, evolve over time. Sometimes this change happens within a single lineage through genetic drift or as its environment changes-i.e., a species with one set of physical characteristics evolves a different set of physical characteristics (Fig. 1). The different stages of this transition are called chronospecies, and they are often given different scientific names. For example, there are currently debates over whether Ardipithicus ramidus is the direct ancestor of $A$. anamensis or merely a close cousin (Fig. 2; White et al. 2006), over whether A. anamensis is the direct ancestor of A. afarensis (Kimbel et al. 2006; see also Strait 2010 in this 


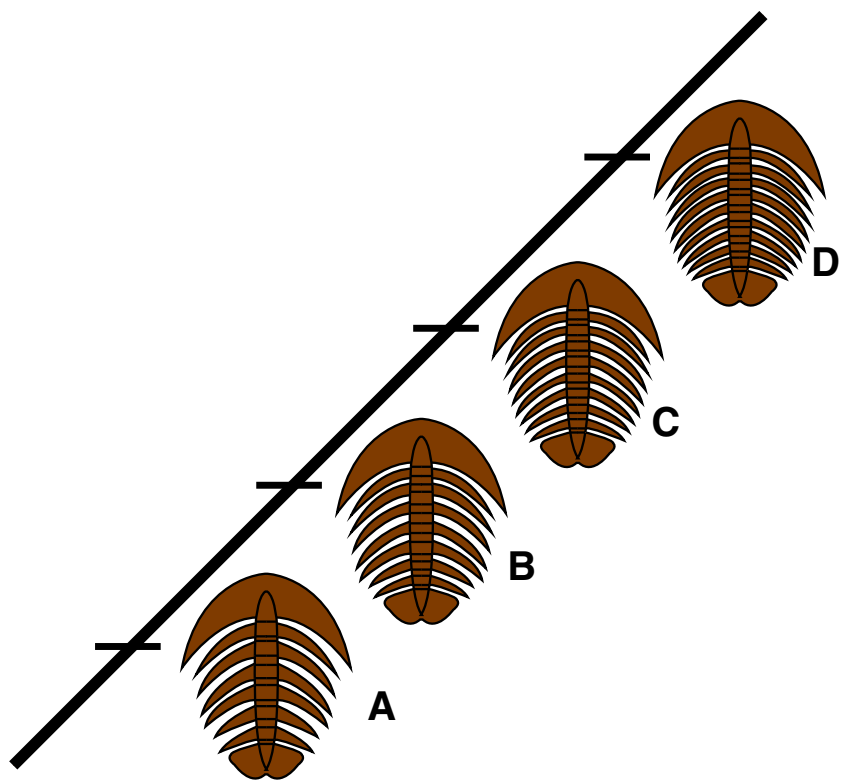

Fig. 1 This trilobite lineage represents a chronospecies. At what point should we consider trilobite A to be a separate species from trilobite Dor should they be considered the same species? Illustration reproduced with permission from the Understanding Evolution website

issue), over whether $A$. afarensis is the direct ancestor of the genus Homo (Leakey et al. 2001; see also Strait 2010 in this issue), and over whether Homo habilis represents a direct ancestor of Homo erectus (Fig. 3; Spoor et al. 2007). If additional fossils from these proposed evolutionary transitions are discovered, will they be given one of the existing names from their lineage or a new name, and how will biologists decide?

The vagaries of and controversies over biological classification help explain some of the frequent name and relationship changes on the human branch of the tree of life. To appropriately interpret these changes, students need not understand details of debates over how species should be defined or over which human relatives represent chronospecies. However, students should be aware that we give names to other organisms for our convenience and that there are many different perspectives on how species

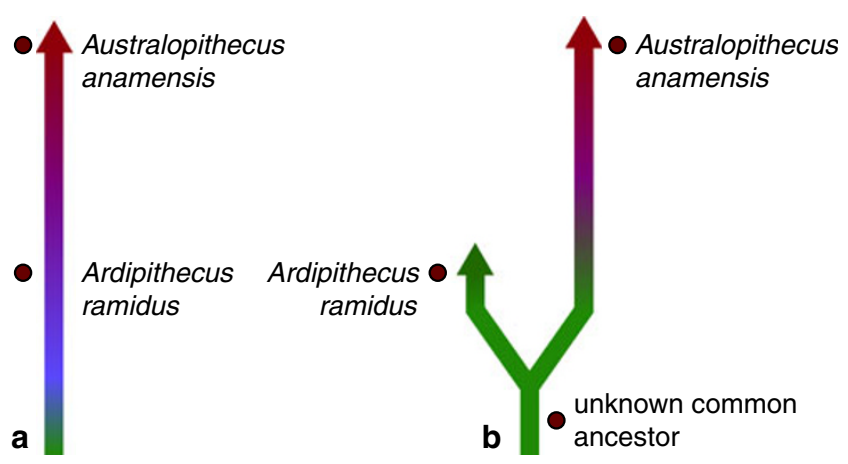

Fig. 2 Two hypotheses regarding the relationship of $A$. ramidus to $A$. anamensis
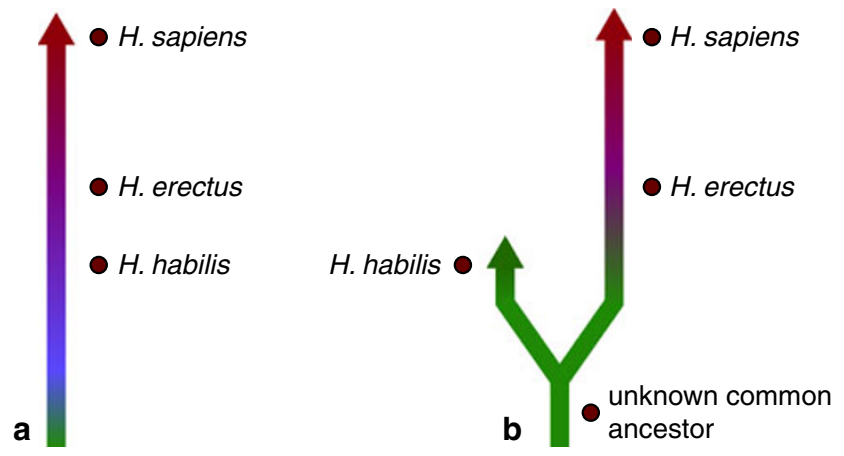

Fig. 3 Two hypotheses regarding the relationship of Homo habilis to modern humans. Illustration reproduced with permission from the Understanding Evolution website

should be defined. Most importantly, students should understand the basic pattern that evolutionary processes yield: evolution produces not discrete bins of organisms, but a continuous web of life - a branching tree of relationships, interconnected from its leaves to its roots. Scientists give names to different twigs for their convenience, but this does not neatly snap the stem from its branch.

\section{Science Thrives on Debate}

Finally, to understand why the hypothesized relationships and names of human relatives keep shifting, students need a basic understanding of the role of debate and controversy in the process of science. True scientific controversy is healthy. It involves disagreements over data interpretation, over which ideas are best supported by the evidence, and over which ideas should be investigated further. This sort of catalyst sparks scrutiny of the existing evidence and encourages additional research, helping science move forward. Scientists regularly disagree with one another and hash it out by carefully examining the evidence. They then revise their ideas based on their interpretations of the evidence. Students should understand that this is a normal part of the process of science - and that the popular press is likely to focus on these controversies and revisions of scientific ideas because they may seem to be more exciting than agreement (e.g., the discovery of yet another line of evidence supporting a currently accepted hypothesis).

Students should also understand that such controversies rarely shake an accepted scientific theory to its core. Most scientific debates take place over less central aspects of an accepted scientific theory. For example, there is some debate about whether $H$. habilis represents a direct ancestor of ours or a close relative of our ancestors (Fig. 3; Spoor et al. 2007). Whichever hypothesis the evidence ultimately supports, a shift in our views of these evolutionary relationships would not constitute a "shake-up" or challenge to evolutionary 
theory itself. Accepted scientific theories, like evolution, are well-tested, thoroughly supported explanations for a broad range of natural phenomena. They encompass many smaller ideas and hypotheses, and when scientists change their minds about these details, it reflects a refinement (not an overthrow) of the over-arching theory. A revision of the shape of our own family tree would represent a small change in a specific portion of our knowledge about the history of life on Earth - but it would change none of the central ideas of evolutionary theory: that life on Earth has evolved, that different species share common ancestors, and that natural selection and other processes lead to evolutionary change.

Biologists expect our view of life's history to change over time. After all, that's what science does: it builds new knowledge of the natural world by continually improving and refining our previous understandings. Scientific theories can be challenged and overthrown, but it takes a preponderance of evidence, a lot of research, and an alternative theory that is a more compelling and useful explanation of how the world actually works. So although scientists are continually refining and improving smaller hypotheses that are a part of evolutionary theory, evolution itself is far from a theory in crisis. Its central ideas are supported by the weight of scientific evidence available, including the fossils from our own ancestors discussed in other articles in this issue.

\section{Conclusion}

Because new research on human evolutionary history receives substantial media attention and because this coverage often highlights controversies, students may get the impression that scientists have little evidence for their ideas about human evolution or that the evidence is equivocal. As emphasized by McNulty (2010) in this issue, neither is accurate. Teachers can help their students put such scientific updates and discoveries in the appropriate context-one that reflects shifting perspectives in biology, new lines of evidence, and the normal process of scienceby helping them understand population thinking, the challenges of biological classification, and the key role of debate and disagreement in scientific progress.

\section{Give Me an Example of That}

Want in-depth examples of how scientists debate different hypotheses regarding human evolutionary history? Check out this resource from the Understanding Evolution website:

- The Genes that Lie Beneath: The Work of Leslea Hlusko. Evolutionary biologist Leslea Hlusko's research takes her from the deserts of Ethiopia, where she hunts for hominid and primate fossils, to a baboon colony in San Antonio, where she takes thousands of measurements of the primates' imposing canines. This research profile describes how Hlusko's work on variation within a baboon population may impact our views on whether A. ramidus is the direct ancestor of $A$. anamensis or merely a close cousin. Read it at http://evolution. berkeley.edu/evolibrary/article/hlusko_01

\section{Branch Out}

As described above, biologists may ascribe to different views about what the definition of a species should be. These different views are intertwined with biologists' perspectives on how organisms should be classified more broadly. To learn more about an important change in how biologists think about classification (i.e., the shift to classifying organisms according to their evolutionary history), check out the following resources:

- Using the Tree for Classification-a brief reader on phylogenetic classification. http://evolution.berkeley.edu/ evolibrary/article/0_0_0/evo_10

- A Name by Any Other Tree-an article on phylogenetic classification from a previous issue of this journal. http:// www.springerlink.com/content/k176638503p63017/

\section{Dig Deeper}

This issue of Evolution: Education and Outreach is largely devoted to modern studies of human evolutionary history. But how did the idea that humans evolved first arise and begin to be accepted? To dig deeper into the history of studies of human evolution, visit this Understanding Evolution resource:

- Fossil Hominids, Human Evolution: Thomas Huxley and Eugene Dubois. This short essay describes Darwin's reticence to discuss human evolution in his work, as well as the subsequent discoveries that helped support the idea that the human species is the result of evolutionary processes. http://evolution.berkeley.edu/ evolibrary/article/_0_0/history_17

Several different perspectives on how species should be defined were briefly described above. To dig deeper into species concepts, visit this Understanding Evolution resource:

- Defining a Species. This tutorial and its side trips review the best known species definition (called the biological species concept), challenges in applying this 
definition, and several other perspectives on how species should be defined. http://evolution.berkeley. edu/evolibrary/article/evo_41

\section{In the Classroom}

You can use different teaching tools to help students tackle the basic concepts they need in order to interpret media coverage of scientific controversies in human evolution. To build students' population thinking skills, try:

- Alike but Not the Same. In this lesson for grades 9-12 from the National Institutes of health, students conduct a class-wide inventory of human traits, construct histograms of the data they collect, and play a brief game that introduces students to major concepts related to human genetic variation. http://science.education.nih. gov/supplements/nih1/Genetic/guide/activity $1 . h t m$

To focus in on classification, try:

- Nuts and Bolts Classification: Arbitrary or Not? In this lesson for grades 6-12 from the Evolution and the Nature of Science Institutes, students work in teams to classify furniture, share their categories and rationales, and note how their different schemes are logical and useful but that they vary and are arbitrary. Students then see how living organisms are classified and note how these natural groupings reflect the same ancestral relationships in the same nested hierarchies, regardless of the different criteria used. This concept is exemplified using primate phylogenetic trees. http://www. indiana.edu/ ensiweb/lessons/cl.intro.html

To help students learn about the role of debate in the process of science, as well as to help them practice analyzing media messages about science, explore the suggested activities for using the Science Toolkit on the Understanding Science website:

- Download a PDF of the toolkit: http://undsci.berkeley. edu/images/science_toolkit.pdf

- Review the concepts behind the toolkit: http://undsci. berkeley.edu/article/sciencetoolkit_01

- Get tips for using the toolkit with students: http://undsci. berkeley.edu/teaching/912 teachingtools.php

Revisit these basic concepts and skills in many different contexts throughout the semester. When students are ready, challenge them to use this knowledge in the context of human evolution with the following lesson and article:

- The Hobbit: When Scientists Disagree About the Evidence. This classroom activity for grades 9-16, adapted from an exercise on PBS's NOVA website and available through the Science Education Resource Center, provides an excellent example of an active debate within the scientific community regarding a relatively recent human fossil find, $H$. floresiensis. The activity highlights the ways in which scientists can interpret scientific evidence in different ways, how scientists build arguments to support their claims, and how assumptions can influence interpretation. Note that you may not want to have students take a poll about which premise is best supported (as recommended in the teacher's guide), since this might give students the incorrect idea that scientific ideas are judged based on popularity. http://serc.carleton. edu/sp/process_of_science/examples/hobbit.html

- When it Comes to Evolution, Headlines Often Get it Wrong. This student-friendly news brief from Understanding Evolution describes how newly discovered fossils are prompting some scientists to consider a minor revision of the relationships shown on the human family tree-specifically, whether $H$. habilis represents a direct ancestor or close relative of $H$. erectus. It also clarifies the occasionally misleading news coverage of the story. Use the questions provided with your students to stimulate classroom discussion. http://evolution.berkeley. edu/evolibrary/news/070901_headlines

Acknowledgements The author wishes to thank Judy Scotchmoor and Jennifer Skene for helpful comments on an earlier draft, as well as David Smith for help developing images.

Open Access This article is distributed under the terms of the Creative Commons Attribution Noncommercial License which permits any noncommercial use, distribution, and reproduction in any medium, provided the original author(s) and source are credited.

\section{References}

Brown P, Sutikna T, Morwood MJ, Soejono RP, Jatmiko, Wahyu Saptomo E, et al. A new small-bodied hominin from the Late Pleistocene of Flores, Indonesia. Nature. 2004;431:1055-61.

Duarte C, Mauricio J, Pettitt PB, Souto P, Trinkaus E, van der Plicht H, et al. The early Upper Paleolithic human skeleton from the Abrigo do Lagar Velho (Portugal) and modern human emergence in Iberia. Proc Natl Acad Sci USA. 1999;96:7604-9.

Green RE, Krause J, Briggs AW, Maricic T, Stenzel U, Kircher M, et al. A draft sequence of the Neandertal genome. Science. 2010;328:710-22.

Harvati K. Neanderthals. Evol Educ Outreach 2010;3, this issue doi:10.1007/s12052-010-0250-0.

Horner JR, Goodwin MB. Extreme cranial ontogeny in the Upper Cretaceous dinosaur Pachycephalosaurus. PLoS ONE. 2009;4: e7626. doi:10.1371/journal.pone.0007626.

Jacob T, Indriati E, Soejono RP, Hsü K, Frayer DW, Eckhardt RB, et al. Pygmoid Australomelanesian Homo sapiens skeletal remains from Liang Bua, Flores: Population affinities and pathological abnormalities. Proc Natl Acad Sci USA. 2006;103:13421-6. 
Kimbel WH, Lockwood CA, Ward CV, Leakey MG, Rak Y, Johanson DC. Was Australopithecus anamensis ancestral to A. afarensis? A case of anagenesis on the hominin fossil record. J Hum Evol. 2006;51:134-52.

Leakey MG, Spoor F, Brown FH, Gathogo PN, Kiarie C, Leakey LN, et al. New hominid genus from eastern Africa shows diverse middle Pliocene lineages. Nature. 2001;410:433-40.

Mayr E. Typological versus population thinking. In: Sober E, editor. Conceptual issues in evolutionary biology. 1st ed. Cambridge: MIT; 1984. p. 14-7.

McBrearty S, Jablonksi NJ. First fossil chimpanzee. Nature. 2005;437:105-8.

McNulty KP. Apes and tricksters: the evolution and diversification of humans' closest relatives. Evol Educ Outreach 2010;3, this issue doi:10.1007/s12052-010-0251-z.

Mishler BD. Getting rid of species? In: Wilson R, editor. Species: New interdisciplinary essays. Cambridge: MIT; 1999. p. 307-15.
Morwood MJ, Brown P, Jatmiko, Sutikna T, Wahyu Saptomo E, Westaway KE, et al. Further evidence for small-bodied hominins from the Late Pleistocene of Flores, Indonesia. Nature. 2005;437:1012-7.

Soficaru A, Petrea C, Dobos A, Trinkaus E. The human cranium from the Peștera Cioclovina Uscată, Romania. Curr Anthropol. 2007;48:611-9.

Spoor F, Leakey MG, Gathogo PN, Brown FH, Antón SC, McDougall I, et al. Implications of new early Homo fossils from Ileret, east of Lake Turkana, Kenya. Nature. 2007;448:688-91.

Strait DS. The evolutionary history of the Australopiths. Evol Educ Outreach 2010;3, this issue doi:10.1007/s12052-010-0249-6.

Thanukos A. Views from Understanding Evolution: A name by any other tree. Evol Educ Outreach. 2009;2:303-9.

White TD, WoldeGabriel G, Asfaw B, Ambrose S, Beyene Y, Bernor RL, et al. Asa Issie, Aramis and the origins of Australopithecus. Nature. 2006;440:883-9. 